\title{
How do cattle respond to sloped floors? An investigation using behavior and electromyograms
}

\author{
E. Rajapaksha and C. B. Tucker ${ }^{1}$ \\ Department of Animal Science, University of California, Davis 95616
}

\begin{abstract}
On dairy farms, flooring is often sloped to facilitate drainage. Sloped floors have been identified as a possible risk factor for lameness, but relatively little is known about how this flooring feature affects dairy cattle. Ours is the first study to evaluate the shortterm effects of floor slope on skeletal muscle activity, restless behavior (measured by number of steps), and latency to lie down after $90 \mathrm{~min}$ of standing. Sixteen Holstein cows were exposed to floors with a $0,3,6$, or $9 \%$ slope in a crossover design, with a minimum of $45 \mathrm{~h}$ between each testing session. Electromyograms were used to evaluate the activity of middle gluteal and biceps femoris muscles. Muscle activity was evaluated in 2 contexts: (1) static muscle contractions when cows continuously transferred weight to each hind leg, before and after 90 min of standing; and (2) dynamic contractions that occurred during $90 \mathrm{~min}$ of treatment exposure. Median power frequency and median amplitude of both static and dynamic muscle electrical signals were calculated. Total muscle activity was calculated using the root mean square of the signals. Restless behavior, the number of steps per treatment, steps and kicks in the milking parlor, and the latency to lie down after the test sessions were also measured. It was predicted that restless behavior, muscle fatigue (as measured by median power frequency and median amplitude), total muscle activity, and latency to lie down after testing would increase with floor slope. However, no treatment differences were found. Median power frequency was significantly greater for the middle gluteal muscle [35 \pm $4 \mathrm{~Hz}$ (mean and SE)] compared with the biceps femoris muscle $(24 \pm 3 \mathrm{~Hz})$, indicating that the contractive properties of these muscles differ. The number of steps per minute and total muscle activity increased significantly over $90 \mathrm{~min}$ of standing, irrespective of floor slope. Although restless behavior and muscle function did not change with slope in our study, this work demonstrates that electromyograms can be used to measure
\end{abstract}

Received August 28, 2013.

Accepted January 28, 2014.

${ }^{1}$ Corresponding author: cbtucker@ucdavis.edu skeletal leg muscle activity in cattle. This technology, along with restless behavior, could be useful in assessing cow comfort in other situations, such as prolonged standing.

Key words: slope, restless behavior, electromyogram, muscle fatigue

\section{INTRODUCTION}

In contemporary commercial dairies, cows spend 11 to $15 \mathrm{~h} / \mathrm{d}$ standing on concrete surfaces in freestall barns (Ito et al., 2009). Comfort while standing has been evaluated in several ways. Behavioral measures include hoof movements, such as lifts, steps, and kicks. All of these parameters increase with standing time (Cooper et al., 2007; Krebs et al., 2011; Chapinal and Tucker, 2012). Stepping and kicking are more common in lame cows (Hassall et al., 1993) and in cows with teat lesions (Rousing et al., 2004). A cow's weight distribution changes during stepping and while standing (Chapinal and Tucker, 2012) and can be measured with load cells. Using this technology, others have found that cows shift their weight more when standing on uncomfortable surfaces (Neveux et al., 2006) and when they are lame (Pastell and Kujala, 2007, Rushen et al., 2007). Variation in weight distribution is reduced when lame cows are given pain medication (Rushen et al., 2007). Together, this evidence indicates that restlessness may be associated with discomfort in dairy cattle.

Human studies also provide insight into methods to assess comfort while standing. Surface electromyography (SEMG) has been used as a noninvasive method to evaluate comfort while standing on different flooring materials (Kim et al., 1994; Cham and Redfern, 2001) and to quantify muscle function and fatigue (a transient decrease in the capacity to perform required physical action; Enoka and Duchateau, 2008) during prolonged standing (De Luca, 1984; Madeleine et al., 1998). Verbal reports of discomfort provided by human test subjects are positively correlated with muscle activity parameters (Kim et al., 1994; Cham and Redfern, 2001). Postural changes or shifts in weight reduce venous pooling in the lower extremities, occlusion of blood flow, and muscular fatigue (Freitas et al., 2005), 
indicating that restless behavior provides physiological benefits.

Surface electromyography measures have been used to evaluate muscle function and fatigue in nonhuman animals, such as horses (Robert et al., 2000; Colborne et al., 2001; Hodson-Tole, 2006; Licka et al., 2009) and dogs (Bockstahler et al., 2009), during exercise in different situations. To our knowledge, skeletal muscle activity has not been studied in cattle in a similar context. Thus, a combination of novel methods of assessment of muscle activity and fatigue, along with restless behavior, may be a promising way to assess discomfort during standing in dairy cattle. In the current study, the focus was on the responses of dairy cattle to sloped floors.

On dairy farms, floors are sloped to facilitate drainage either in the home pens or in the holding pens of the milking area. The magnitude of the slope varies between 0 and $10 \%$ depending on the farm and the location within the facility (Bartussek, 1993; Chiappini and Zappavigna, 1993). Relatively little is known about how cattle respond to sloped floors, although this feature has been identified as a risk factor for laminitis in an epidemiological study (Philipot et al., 1994). Cows may stand on sloped floors in the holding pen from 15 min to more than $3 \mathrm{~h} / \mathrm{d}$ (Cook and Nordlund, 2009) or spend 11 to $15 \mathrm{~h} / \mathrm{d}$ in freestall barns (Ito et al., 2009). In the current work, the short-term response to slope was evaluated during $90 \mathrm{~min}$ of standing, an estimate of average standing time before milking, as relatively little is known about how long cattle wait on most farms. Thus, the objectives of the current study were to investigate the potential of using SEMG methodology in dairy cows and to evaluate cattle short-term responses to standing on sloped floors. It was predicted that, as the slope of the floor increased, cows would show more restless behavior, increased total muscle activity, and indicators of muscle fatigue as measured by decreased median power frequency (MPF) and increased median amplitude (MA).

\section{MATERIALS AND METHODS}

\section{General Information}

This experiment was conducted at the University of California, Davis, dairy facility between April and June of 2010. All procedures were approved by the Institutional Animal Care and Use Committee.

\section{Animals and Housing}

Sixteen lactating Holstein-Friesian dairy cows were tested in groups of 4 . All were clinically sound, with gait scores $\leq 2$ (Flower and Weary, 2006). Cows had an average BW of $647 \pm 102 \mathrm{~kg}$, BCS of $2.9 \pm 0.3$, DIM of $69 \pm 28$, and daily milk production (evaluated weekly) of $39.8 \pm 11.4 \mathrm{~kg}$. Animals were housed in a pen with 24 head-to-head freestalls $(1.2 \times 2.4 \mathrm{~m} ; 1$ cow/freestall $)$ deep-bedded with sand and with a neck rail located at $106 \pm 2 \mathrm{~cm}$ above the stall surface. The cows were milked twice daily, at 0600 and $1700 \mathrm{~h}$, had ad libitum access to water, and were fed a TMR consisting of $37 \%$ alfalfa hay, $36 \%$ grain mix, $10 \%$ whole cotton seed, $12 \%$ almond hulls, $2 \%$ soybean meal, and $3 \%$ mineral mix on a DM basis. They were fed 3 times a day, at 0400 , 1100 , and $1600 \mathrm{~h}$.

\section{Experimental Procedures}

During the experiment, animals were moved to a test ramp located $100 \mathrm{~m}$ away from their freestall pen. The test ramp was made out of steel and had a wooden floor covered with rubber mats that were twice as compressible as concrete (19-mm thick; Animat, Animat Inc., Saint-Élie d'Orford, Quebec, Canada). The floor of the ramp was divided into 2 sections (both 2.4-m long and $1.2-\mathrm{m}$ wide): a fixed section with $0 \%$ slope and an adjustable section with a mechanism that allowed it to be lifted to create the treatment slopes of $0,3,6$, and $9 \%$. Cows had 8 training sessions to habituate them to standing on the ramp; during these sessions they were offered with a mixture of grain and their regular diet as a reward. During testing, cows were first prepped and tested on the nonmovable flat portion of the ramp (details described herein) and then were restricted to the sloped portion of the ramp for $90 \mathrm{~min}$. Cows were exposed to each of the 4 treatments in a crossover design, with the order of treatments exposure balanced across cows and within groups of 4 . No food was available during these test sessions, except a cup of grain given at the end of each. Elapsed time between each treatment was 45 to $46 \mathrm{~h}$.

\section{Measures: SEMG Evaluation}

During test sessions, animals were first brought on to the nonmovable, flat section of the ramp and prepared for SEMG evaluation. Two muscles important in standing and stepping, the middle gluteal (an extensor of the hip joint and abductor of the limb that control hip movements) and biceps femoris (extensor of the hip and stifle and flexure of the stifle), were evaluated. Eight self-adhesive bipolar surface electrodes (3M Red Dot Repositionable Electrodes, Ag/AgCl; 3M, St. Paul, MN) with a $10.1-\mathrm{cm}^{2}$ conductive area were placed over the center of biceps femoris and middle gluteal on both sides of the cow. Decisions about electrode placement sites on the muscles were based on 
the information gathered by examining muscle samples from slaughtered cattle and from previous work with horses (Robert et al., 2000). Electrode application sites were clipped, shaved, cleaned with an isopropyl alcohol solution, and scrubbed using electrical conductionenhancing scrubbing gel (D.O. Weaver NuPrep Skin Prep Gel, Weaver and Co., Aurora, CO) before placing the electrodes. Two bipolar electrodes were placed on each muscle parallel to the muscle fiber direction with a 3 -cm intraelectrode distance. The ground electrode for each corresponding bipolar electrode was placed $10 \mathrm{~cm}$ away from the reading electrodes. After the electrodes had been positioned, micropore paper tape (3M Micropore Medical Tape) was placed over them to minimize any signal noise created by movement of the electrodes. Surface electromyography data were collected using an EMG telemetric system (Megawin Biomonitor ME 6000, Mega Electronics Ltd., Kuopio, Finland) that was hung in the space above the cow on the railing. Muscle activity was recorded during both static and dynamic contractions (described herein). All SEMG signals recorded at a sample rate of $1,000 \mathrm{~Hz}$ were preamplified (input impedance $=10 \mathrm{G} \Omega$, gain $=305$ ) and a low-pass Butterworth filter (bandwidth $=8-500 \mathrm{~Hz}$ ) was used. Common mode rejection ratio for the instrument was $110 \mathrm{~dB}$. Data recording and preparation for analysis was done with Megawin version 2.3 software (Mega Electronics Ltd.). Recorded raw signals were Fast Fourier transformed for frequency domain analysis and SEMG power spectrums were used to acquire MPF values for all muscle contractions. Root mean square averages of the raw signals were used for MA and total muscle activity calculations.

\section{Static Contractions Before and After Treatments}

Static contractions were measured while animals were restricted to the nonmovable flat section of the ramp, before and after $90 \mathrm{~min}$ of standing on a given slope. This information was used in 2 ways. First, "before" values served as a reference contraction to normalize SEMG readings. Second, comparisons of readings before and after testing were used to assess muscle fatigue during static contractions. To generate these contractions, cattle were forced to transfer their weight on a single hind leg, by sliding a wooden board that had carriage bolts protruding from it a method similar the one used by Neveux et al. (2006). Top contact surface of the wooden board was covered by a thin rubber mat to avoid injuries to the hooves. This procedure caused the contralateral hind leg (leg that was not on the wooden board) to perform more work than when both hooves were on the same surface. This reading, which was a reference volumetric contraction, was recorded for each side for both muscles for $30 \mathrm{~s}$. Differences (after vs. before) were taken for MPF and MA for values from static contractions to evaluate muscle fatigue (defined as decreased MPF and increased MA; Hägg et al., 2000).

\section{Dynamic Contractions During Treatments}

Continuous SEMG recordings during standing were recorded in 90-min test sessions when cows were restricted on the adjustable portion of the ramp. In addition, a subset of dynamic contractions (steps) that occurred during this time was also evaluated to assess muscle fatigue during dynamic contractions. Six hind leg steps within the first 15 min (start) and 6 within the last 15 min of standing (end) were identified. When identifying the 6 steps to use, the first 3 sets of right-left consecutive events (1 step/leg) were chosen to ensure consistency. Muscle activity associated with these steps was used to calculate MPF and MA for the 2 time periods. The differences between MPF and MA values at the start and end were used to evaluate fatigue during dynamic contractions. The total muscle activity (associated with all steps and any weight shifting) during the 90-min period was calculated for each slope.

\section{Behavior Observations}

Behavioral observations were conducted in 3 situations.

Stepping Behavior During Treatments. All steps during the 90-min tests were recorded continuously with WV-BP334 black-and-white closed-circuit television video cameras (Panasonic Corporation of North America, Secaucus, NJ) and 13VG2812ASII lenses (Tamron, Commack, NY) connected to a digital video recorder with a GV-1120/1240/1480 combo card (USA Vision Systems Inc., Irvine, CA) and IPD-NVR16 digital surveillance software (Clearvision Inc., Wheeling, IL). Four cameras were positioned around the ramp and each camera was set to record at medium quality, 30 frames/s. A step was defined as lifting any part of the hoof off the ground. Steps were recorded separately for all 4 limbs and were analyzed as front, hind, or total number of steps. Video recordings of 64 testing sessions were analyzed by 3 trained observers. These observers had more than $94 \%$ intra- and interobserver reliability, as measured by correlation.

Stepping and Kicking in the Milking Parlor. After each test session, cows were walked to the parlor for routine milking. Kicking and stepping were recorded during milking time $(9 \pm 2$ min; mean \pm SD $)$ by 9 observers using a digital audio recorder (digital voice recorder, model ICD BX800, Sony Europe Ltd., 
Weybridge, UK). A step was defined as lifting any part of the hoof off the ground, in any direction, to a height below the level of dewclaws of the opposite leg. A kick was defined as lifting of the entire hoof off the ground above the level of dewclaws of the opposite leg. At least $85 \%$ interobserver reliability was observed for all observers measured by percentage of agreement with an experienced observer.

Lying and Standing Behavior. Both lying and standing behavior were recorded with Onset Pendant G data loggers (64k, Onset Computer Corp., Bourne, MA) set to record the y-axis at 30-s intervals. Procedures reported by Ledgerwood et al. (2010) were followed for attachment of data loggers and data handling; single 30 -s standing or lying events were deleted. The loggers were wrapped in cloth and VetWrap cohesive bandage $(3 \mathrm{M})$ and placed directly toward medial plane of the leg. Latency to lie down after testing (after milking) and length of the last standing and lying bouts occurring immediately before each test session were extracted from the recorded data.

\section{Statistical Analysis}

All statistical analyses were conducted with the cow as the experimental unit. Steps per minute, total number of steps and kicks per minute in the milking parlor, and latency to lie down were analyzed using a general linear model (PROC GLM; SAS Institute, 2012). Residuals were examined to verify normality and homogeneity of variances. The model included terms for group (cow), order of exposure to each treatment, and treatment. Treatment was imposed in a doseresponse manner; thus, for these overall effects, this term was divided into its linear, quadratic, and cubic components within the model. Because both standing time and lying time immediately before each test session may have influenced the responses, a ratio of these was calculated and used as a covariate in this model. Significant treatment quadratic $(P \geq 0.184)$ or cubic $(P \geq 0.333)$ effects were not observed; thus, only the $P$-values for the linear effect are reported. Similarly, the covariate was never significant and was removed from the analysis. To examine the effect of time within the 90-min test, steps per minute was divided in to six 15 -min intervals. These values were then tested in a separate model that included terms for group (cow), order of exposure to each treatment, time, treatment, and time $\times$ treatment. The $P$-values were corrected using Greenhouse-Geisser.

Surface electromyography values MPF and MA from the left and right side of both muscles were averaged for further analysis. As the residuals for muscle fatigue parameters (difference in MPF and MA) were not nor- mally distributed for either static or dynamic contractions and could not be corrected by transformations, the nonparametric Page's L-test (Page, 1963) was used to test for the linear trend between the treatments. Total muscle activity during the 90-min period and changes in total muscle activity over time (divided into 15-min intervals, as previously described) were analyzed using the same statistical models used for stepping behavior analysis. To compare activity of the 2 muscles, biceps femoris and middle gluteal, the MPF and total activity value per muscle were averaged for all 4 slopes and were compared with paired $t$-test (PROC TTEST). The correlation among behavioral parameters and between behavioral and muscle activity parameters was explored by Pearson correlation analysis separately for each treatment (PROC CORR).

\section{RESULTS}

\section{Behavioral Observations}

No significant treatment differences were observed for the average number of steps per minute for all 4 legs, front legs, or back legs during the 90-min test $(P$ $\geq 0.604, \mathrm{~F}_{1,40} \leq 0.87$; Table 1$)$, nor were any behavioral differences in the milking parlor observed $(P=0.164$, $\mathrm{F}_{1,40}=2.01$; Table 1). Cattle that stepped frequently on the test surface were also more likely to step or kick in the parlor (positive correlation for 0,3 , and $9 \%$ treatments; $\mathrm{r} \geq 0.79, P \leq 0.001$; Figure 1$)$. This trend was also apparent for the $6 \%$ slope $(\mathrm{r}=0.45, P=0.083$, Figure 1). In addition, steps per minute increased with time on the testing surface $\left(P<0.001, \mathrm{~F}_{5,210}=23.91\right.$; Figure 2). No interactions between time and treatment $(P=0.588)$ were observed. On average, cows in this experiment spent $11 \pm 1.5 \mathrm{~h} / \mathrm{d}$ lying down and had 10 \pm 3 lying bouts/d (mean $\pm \mathrm{SD}$ ). No significant treatment differences were noted in the latency to lie down after testing $(84 \pm 45.5$ min; mean $\pm \mathrm{SD} ; P=0.733$, $\left.\mathrm{F}_{1,40}=0.12\right)$. Similarly, no significant differences among treatments $\left(P \geq 0.565, \mathrm{~F}_{1,40} \geq 0.34\right)$ were observed in either standing or lying time immediately before the cows were tested on the treatment slopes.

\section{SEMG Evaluation}

For both static and dynamic contractions, no significant treatment differences were observed for the difference of MPF or MA between start and end times [Page (1963) L statistic was MPF $\leq 412$ and MA $\leq 418$, the test statistic for this sample size becomes statistically significant $(P<0.05)$ when $\mathrm{L}=420]$. Total muscle activity during the $90 \mathrm{~min}$ of standing did not differ among treatments $\left(P=0.114, \mathrm{~F}_{1,40}=2.06\right)$, nor be- 
Table 1. Steps per minute (LSM) during $90 \mathrm{~min}$ of standing on each treatment floor $(0,3,6$, or $9 \%$ slope) and steps and kicks per minute (LSM) at the milking parlor after testing

\begin{tabular}{lllllll}
\hline & \multicolumn{9}{c}{ Slope } & & \\
\cline { 2 - 5 } Behavior & $0 \%$ & $3 \%$ & $6 \%$ & $9 \%$ & SE & $P$-value \\
\hline Steps & 5.5 & 5.7 & 6.1 & 5.6 & 0.30 & 0.872 \\
$\quad$ All 4 legs & 3.8 & 4.0 & 4.4 & 4.0 & 0.21 & 0.604 \\
$\quad$ Front legs & 1.6 & 1.7 & 1.7 & 1.7 & 0.13 & 0.649 \\
$\quad$ Back legs & 2.8 & 3.2 & 2.8 & 3.6 & 0.26 & 0.164 \\
$\quad$ In the milking parlor & & & & & &
\end{tabular}

tween muscles $(P=0.775)$. Total muscle activity significantly increased as cows spent more time standing $\left(P<0.001, \mathrm{~F}_{5,210}=6.18 ;\right.$ Figure 2$)$, but no interaction was seen between time and treatment $(P=0.489)$. No relationship was observed between the steps per minute and total muscle activity per minute in the hind legs $(0.45 \leq \mathrm{r} \geq-0.37 ; P \geq 0.162)$ except for a trend in the $6 \%$ treatment $(P=0.078)$. The biceps femoris muscle MPF values were significantly less than those of the middle gluteal muscle for both types of contractions (Table 2), regardless of slope.

\section{DISCUSSION}

Our work is the first to use SEMG to measure muscle activity in cattle. Neither muscle activity nor restless behavior was affected by the floor slope during $90 \mathrm{~min}$ of standing. Restless behavior and total muscle activity both increased with time spent standing irrespective

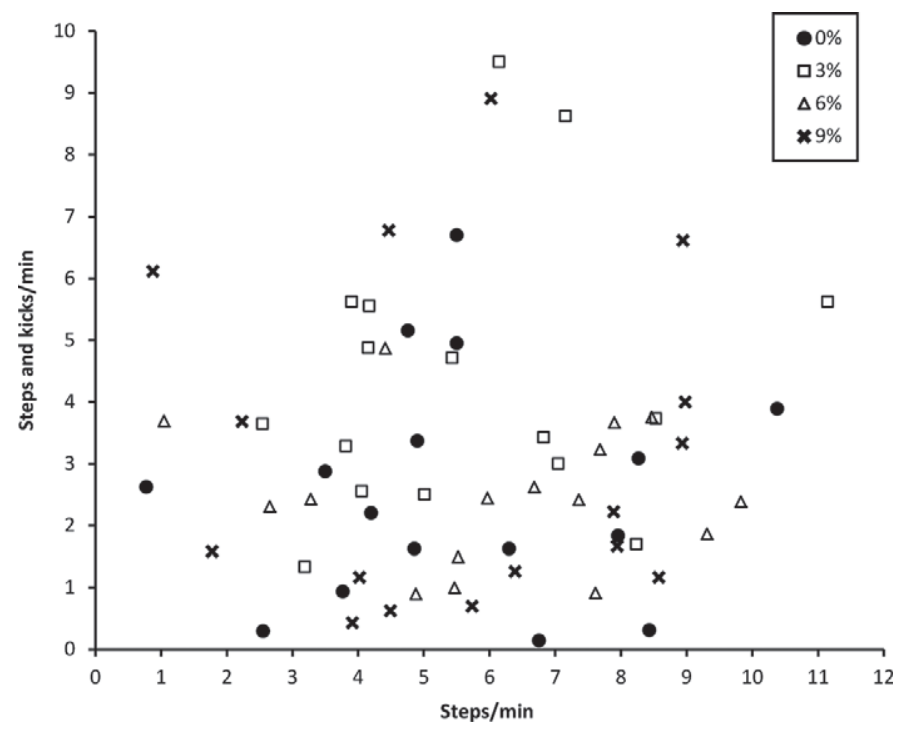

Figure 1. Relationship between steps per minute on 1 of 4 floor slopes $(0,3,6$, or $9 \%)$ during 90 min of standing and the number of steps and kicks per minute in the milking parlor following that period of forced standing. of treatment, despite no correlation existing between these parameters. In addition, differences were noted in the MPF values between the 2 muscles tested, indicating different contractile properties.

In agreement with previous work (Cooper et al., 2007; Krebs et al., 2011; Chapinal and Tucker, 2012), steps per minute increased with standing time, regardless of flooring treatment. Total muscle activity also increased over the 90-min test period, although these values were not correlated with stepping behavior, perhaps because additional movements that are more subtle than steps (e.g., weight shifts without stepping) also require muscle contraction. Indeed, others have also shown that variation in weight distribution increases with time spent standing and is not necessarily correlated with stepping behavior (Chapinal and Tucker, 2012). The function of these steps and muscle contractions during standing bouts is unknown, but cattle may engage in more restless behavior the longer they stand to increase blood circulation to muscle and reduce venous pooling of blood in the muscles. Both these mechanisms are used to reduce muscle fatigue and discomfort in humans (Freitas et al., 2005). In the current study, no evidence of muscle fatigue was found, and measures of circulation were not included. Perhaps, in future work, these variables could provide insight into functional reasons why restless behavior and muscle activity increase with standing time.

It is also unclear what an increased stepping rate and muscle activity reflects in terms of comfort for the cow. Before this experiment, evidence suggested that an increase in stepping indicates discomfort, as lame cows step more often than sound ones, and animals forced to stand on an uncomfortable surface step more than those on soft rubber floor (Neveux et al., 2006; Rushen et al., 2007). However, in the current study, only limited evidence was observed that the increase seen in stepping rate or muscle activity indicates discomfort. First, steps on the treatment surface correlated with stepping or kicking behavior in the milking parlor, indicating that individual differences exist in propensity to perform these behaviors among a population of sound 
Table 2. Median power frequency values (LSM \pm SE) measured between 2 muscles when cows are forced to transfer weight to 1 hind leg (static contractions) and for 6 steps (dynamic contractions) on floors that were 1 of 4 slopes $(0,3,6$, or $9 \%)$

\begin{tabular}{|c|c|c|c|}
\hline \multirow[b]{2}{*}{ Slope } & \multicolumn{2}{|c|}{ Muscle } & \multirow[b]{2}{*}{$P$-value } \\
\hline & $\begin{array}{l}\text { Biceps } \\
\text { femoris }\end{array}$ & $\begin{array}{l}\text { Middle } \\
\text { gluteal }\end{array}$ & \\
\hline \multicolumn{4}{|c|}{ Static contractions $(\mathrm{Hz})$} \\
\hline $0 \%$ & $27 \pm 4.1$ & $34 \pm 4.7$ & 0.020 \\
\hline $3 \%$ & $24 \pm 4.7$ & $33 \pm 6.5$ & 0.013 \\
\hline $6 \%$ & $24 \pm 2.7$ & $34 \pm 7.7$ & 0.006 \\
\hline $9 \%$ & $23 \pm 3.2$ & $31 \pm 5.1$ & 0.003 \\
\hline \multicolumn{4}{|c|}{ Dynamic contractions $(\mathrm{Hz})$} \\
\hline $0 \%$ & $28 \pm 3.5$ & $36 \pm 3.7$ & 0.001 \\
\hline $3 \%$ & $28 \pm 4.7$ & $34 \pm 5.5$ & 0.043 \\
\hline $6 \%$ & $27 \pm 3.1$ & $37 \pm 1.5$ & 0.001 \\
\hline $9 \%$ & $26 \pm 3.5$ & $36 \pm 4.7$ & $<0.001$ \\
\hline
\end{tabular}

dairy cattle. Second, cattle were not quick to lie down after the test scenario (90 min of testing followed by milking time); average latency to lie down was $84 \mathrm{~min}$. This is considerably longer than the 5-min latency to lie down after $4 \mathrm{~h}$ of standing seen in other studies (Krebs et al., 2011). Indeed, it is known that cattle are averse to long periods of standing: they will choose comfort by lying over feeding after $3 \mathrm{~h}$ of deprivation of both (Metz, 1985). Thus, it remains unclear if the increase in stepping rate and muscle activity during $90 \mathrm{~min}$ of standing indicates discomfort. Further work is required to understand if this time-related restless behavior is equivalent to the discomfort-associated restless behavior seen in other work.

Little work has evaluated the effect of floor slope on dairy cows, although it has been identified as a risk factor for laminitis (Philipot et al., 1994). In a study by Vokey et al. (2003), cows standing on 5\% sloped floor for $4.5 \mathrm{~h} / \mathrm{d}$ for $112 \mathrm{~d}$ had better claw lesion scores over time than cows that stood on a flat floor. This positive effect on hoof health can mainly be attributed to the better drainage on sloped surfaces, as exposure to moisture and manure is known to decrease claw integrity (Borderas et al., 2004). The current study, designed to evaluate the short-term effects of standing on sloped floors, did not find any effect on behavior or muscle activity. Similarly, others have also been unsuccessful at using restless behavior to distinguish cows' responses to rubber and concrete flooring when they stand on them with all 4 hooves (Krebs et al., 2011), although cows show a preference for rubber over concrete flooring during standing (Telezhenko et al., 2007). Collectively, these studies give rise to questions about how to assess discomfort in cattle. Previous work in cattle that identified discomfort while standing through increased stepping used a stimulus in a single hoof (lameness, uncomfortable flooring), whereas the treatment was
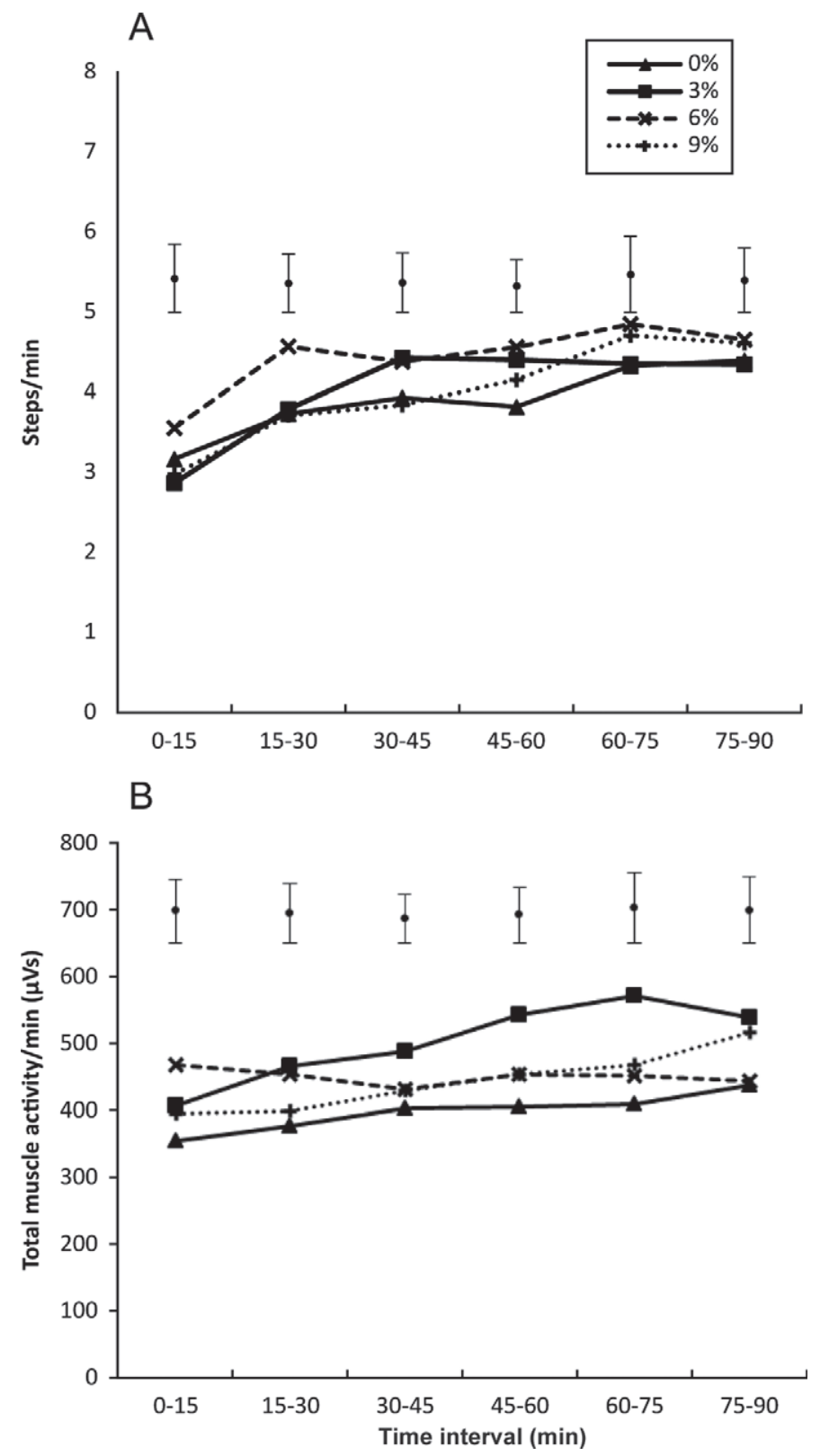

Figure 2. Average (LSM) total muscle activity per minute (A) and steps per minute (B) in relation to 15 -min time intervals during the 90-min standing period on each slope floor $(0,3,6$, or $9 \%)$. Pooled $\mathrm{SE}$ values are shown separately for each time point with error bars on conveniently selected correlating data points for clear visibility.

performed under all 4 legs in the current study. It is possible that restlessness is a better indicator of discomfort when the aversive stimulus is under a single leg, as the animal can shift its weight away from the affected limb. The findings of the current study indicate that interpretation of restless behavior as a measure of discomfort is not straightforward and requires further evaluation.

Previous research in other species has shown muscle activity increases in relation to sloped floors. In humans, 
standing on a slope for 48 min increased muscle activity (Gallagher et al., 2013), and, in horses, 2 min of walking on inclined surfaces caused an increase in muscle activity (Robert et al., 2000). In the current study, both fatigue parameters evaluated (MPF and MA difference between start and end) did not show significant differences for either muscle during the 90 min of standing time. Similarly, total muscle activity did not differ with floor slope. Several possible explanations exist for the lack of differences. First, cows stood on rubber mats, which may have mitigated some discomfort. Second, testing for only $90 \mathrm{~min}$ may have limited the ability to detect differences. Although an increase in muscle activity was seen over time, skeletal muscles of cows may be adapted to withstand longer standing times without fatigue. Ninety minutes of standing time was chosen as an estimate for standing time before milking and thought to be representative of what might happen on a commercial farm; K. Ito (Novus International Inc., St. Charles, MO, personal communication) reported 2.7 $\pm 1.1 \mathrm{~h}$ and $1.8 \mathrm{~h}$ average time out of the pen for milking, respectively, with maximum milking times of 6.0 h/d (Gomez and Cook, 2010) or 3 h 50 min (K. Ito, Novus International Inc., St. Charles, MO, personal communication), indicating that standing times longer than 90 min occur on dairy farms. In addition, due to established milking order (Rathore, 1982), cows that are late to enter the milking parlor are likely to consistently stand for longer periods of time in the holding area. Therefore, evaluating restless behavior along with muscle activity may provide insight into how cattle respond to these prolonged standing situations.

Two muscles were compared to better understand the involvement of each in the standing function in cows. Although the overall muscle activity was similar between muscle types, the MPF was significantly higher in the middle gluteal muscle than in the biceps femoris during both static and dynamic contractions. This finding was interesting because the middle gluteal muscle is smaller, yet it performed more work during both static and dynamic contractions. A study that compared middle gluteal and tensor fasciae latae in horses found a similar pattern, with more total activity in the middle gluteal muscle (Robert et al., 2000). This highlights the variability of muscles in SEMG evaluation and, along with other methodological considerations discussed herein, such as treatments under 1 or all 4 hooves and duration of standing, are all important considerations for future work with this technology.

\section{CONCLUSIONS}

Restless behavior and muscle activity did not change with floor slope up to $9 \%$ during 90 min of standing, although they both increased with time. The current study demonstrated that SEMG can be used to measure skeletal muscle activity in cattle while standing. No muscle fatigue was observed in our study, and more research is needed to evaluate this phenomenon in cows. Surface electromyography, along with restless behavior, may be useful in assessing cattle responses in other situations, such as prolonged standing.

\section{ACKNOWLEDGMENTS}

This research was supported by W.K. Kellogg Endowment, Lyons fellowship (Battle Creek, MI; funding for E. Rajapaksha), and USDA National Institute of Food and Agriculture (Washington, DC) Multistate Research Project NC1029. We gratefully acknowledge the infrastructure support of the Department of Animal Science, College of Agricultural and Environmental Sciences, and the California Agricultural Experiment Station of the University of California, Davis. We thank University of California Davis dairy farm manager Doug Gisi, as well as Amanda Grout and the undergraduate interns for their help throughout the experiments. We are also grateful to Susan Stover, Tanya Gracia (University of California, Davis, Veterinary orthopedic laboratory) and David Hawkins (University of California, Davis) for their input in preparation for the study and SEMG techniques.

\section{REFERENCES}

Bartussek, H. 1993. Sloped floor systems for dairy cows: New experience in Austria. Pages 986-992 in Proc. Livest. Environ. IV., Coventry, UK. American Society of Agricultural Engineers (ASAE), St. Joseph, MI.

Bockstahler, B. B., R. Gesky, M. Mueller, J. G. Thalhammer, C. Peham, and I. Podbregar. 2009. Correlation of surface electromyography of the Vastus lateralis muscle in dogs at a walk with joint kinematics and ground reaction forces. Vet. Surg. 38:754-761.

Borderas, T. F., B. Pawluczuk, A. M. de Passillé, and J. Rushen. 2004. Claw hardness of dairy cows: Relationship to water content and claw lesions. J. Dairy Sci. 87:2085-2093.

Cham, R., and M. S. R. Redfern. 2001. Effect of flooring on standing comfort and fatigue. Hum. Factors 43:381-391.

Chapinal, N., and C. B. Tucker. 2012. Validation of an automated method to count steps while cows stand on a weighing platform and its application as a measure to detect lameness. J. Dairy Sci. 95:6523-6528.

Chiappini, U., and P. Zappavigna. 1993. Experimental tests on sloped bedded floors for dairy cows. Pages 1001-1005 in Proc. Livest. Environ. IV., Coventry, UK. American Society of Agricultural Engineers (ASAE), St. Joseph, MI.

Colborne, G. R., D. M. Birtles, and I. C. Cacchione. 2001. Electromyographic and kinematic indicators of fatigue in horses: A pilot study. Equine Vet. J. Suppl. 33:89-93.

Cook, N. B., and K. V. Nordlund. 2009. The influence of the environment on dairy cow behavior, claw health and herd lameness dynamics. Vet. J. 179:360-369.

Cooper, M. D., D. R. Arney, and C. J. Phillips. 2007. Two- or fourhour lying deprivation on the behavior of lactating dairy cows. J. Dairy Sci. 90:1149-1158. 
De Luca, C. J. 1984. Myoelectric manifestations of localised muscular fatigue in humans. Crit. Rev. Biomed. Eng. 11:251-279.

Enoka, R. M., and J. Duchateau. 2008. Muscle fatigue: What, why and how it influences muscle function. J. Physiol. 586:11-23.

Flower, F. C., and D. M. Weary. 2006. Effect of hoof pathologies on subjective assessments of dairy cow gait. J. Dairy Sci. 89:139-146.

Freitas, S. M. S. F., S. A. Wieczorek, P. H. Marchetti, and M. Duarte. 2005. Age-related changes in human postural control of prolonged standing. Gait Posture 22:322-330.

Gallagher, K. M., E. Nelson-Wong, and J. P. Callaghan. 2013. Possible mechanisms for the reduction of low back pain associated with standing on a sloped surface. Gait Posture 37:313-318.

Gomez, A., and N. B. Cook. 2010. Time budgets of lactating dairy cattle in commercial freestall herds. J. Dairy Sci. 93:5772-5781.

Hägg, G. M., A. Luttmann, and M. Jäger. 2000. Methodologies for evaluating electromyographic field data in ergonomics. J. Electromyogr. Kinesiol. 10:301-312.

Hassall, S. A., W. R. Ward, and R. D. Murray. 1993. Effects of lameness on the behaviour of cows during the summer. Vet. Rec. 132:578-580.

Hodson-Tole, E. 2006. Effects of treadmill inclination and speed on forelimb muscle activity and kinematics in the horse. Equine Comp. Exer. Physiol. 3:61-72.

Ito, K., D. M. Weary, and M. A. G. von Keyserlingk. 2009. Lying behavior: Assessing within and between herd variation in freestall housed dairy cows. J. Dairy Sci. 92:4412-4420.

Kim, J. Y., C. Stuart-Buttle, and W. S. Marras. 1994. The effects of mats on back and leg fatigue. Appl. Ergon. 25:29-34.

Krebs, N., S. L. Berry, and C. B. Tucker. 2011. Restless behavior increases over time, but not with compressibility of the flooring surface, during forced standing at the feed bunk. J. Dairy Sci. 94:97-105.

Ledgerwood, D. N., C. Winckler, and C. B. Tucker. 2010. Evaluation of data loggers, sampling intervals, and editing techniques for measuring lying behavior of dairy cattle. J. Dairy Sci. 93:5129-5139.

Licka, T., A. Frey, and C. Peham. 2009. Electromyographic activity of the longissimus dorsi muscles in horses when walking on a treadmill. Vet. J. 180:71-76.
Madeleine, P., M. Voigt, and L. Arendt-Nielsen. 1998. Subjective, physiological and biomechanical responses to prolonged manual work performed standing on hard and soft surfaces. Eur. J. Appl. Occup. Physiol. 77:1-9.

Metz, J. H. M. 1985. The reaction of cows to a short-term deprivation of lying. Appl. Anim. Behav. Sci. 13:301-307.

Neveux, S., D. M. Weary, J. Rushen, M. A. G. von Keyserlingk, and A. M. de Passillé. 2006. Hoof discomfort changes how dairy cattle distribute their body weight. J. Dairy Sci. 89:2503-2509.

Page, E. B. 1963. Ordered hypotheses for multiple treatments: A significance test for linear ranks. J. Am. Stat. Assoc. 58:216-230.

Pastell, M. E., and M. Kujala. 2007. A probabilistic neural network model for lameness detection. J. Dairy Sci. 90:2283-2292.

Philipot, J. M., P. Pluvinage, I. Cimarosti, P. Sulpice, and F. Bugnard. 1994. Risk factors of dairy cow lameness associated with housing conditions. Vet. Res. 25:244-248.

Rathore, A. K. 1982. Order of cow entry at milking and its relationships with milk yield and consistency of the order. Appl. Anim. Ethol. 8:45-52.

Robert, C.. J. P. Valette, and J. M. Denoix. 2000. The effects of treadmill inclination and speed on the activity of two hindlimb muscles in the trotting horse. Equine Vet. J. 32:312-317.

Rousing, T., M. Bonde, J. H. Badsberg, and J. T. Sørensen. 2004. Stepping and kicking behaviour during milking in relation to response in human-animal interaction test and clinical health in loose housed dairy cows. Livest. Prod. Sci. 88:1-8.

Rushen, J., E. Pombourcq, and A. M. de Passillé. 2007. Validation of two measures of lameness in dairy cows. Appl. Anim. Behav. Sci. 106:173-177.

SAS Institute. 2012. SAS/STAT Software. Version 9.2 Edition. SAS Inst. Inc., Cary, NC.

Telezhenko, E., L. Lidfors, and C. Bergsten. 2007. Dairy cow preferences for soft or hard flooring when standing or walking. J. Dairy Sci. 90:3716-3724.

Vokey, F. J., C. L. Guard, H. N. Erb, and D. M. Galton. 2003. Observation on flooring and stall surfaces for dairy cattle housed in a freestall barn. Pages 165-170 in Proc. Dairy Housing Conf., Fort Worth, TX. Am. Soc. Agric. Eng., St. Joseph, MI. 